\title{
A novel paradigm for rapid ABT-737-induced apoptosis involving outer mitochondrial membrane rupture in primary leukemia and lymphoma cells
}

\author{
M Vogler ${ }^{1}$, D Dinsdale ${ }^{1}$, X-M Sun ${ }^{1}$, KW Young ${ }^{1}$, M Butterworth ${ }^{1}$, P Nicotera ${ }^{1}$, MJS Dyer $^{1}$ and GM Cohen ${ }^{\star, 1}$
}

Primary chronic lymphocytic leukemia (CLL) cells are exquisitely sensitive to ABT-737, a small molecule BCL2-antagonist, which induces many of the classical biochemical and ultrastructural features of apoptosis, including BAX/BAK oligomerization, cytochrome $c$ release, caspase activation and chromatin condensation. Surprisingly, ABT-737 also induces mitochondrial inner membrane permeabilization (MIMP) resulting in mitochondrial matrix swelling and rupture of the outer mitochondrial membrane (OMM), so permitting the rapid efflux of cytochrome $c$ from mitochondrial cristae and facilitating rapid caspase activation and apoptosis. BAX and BAK appear to be involved in the OMM discontinuities as they localize to the OMM break points. Notably, ABT-737 induced mitochondrial matrix swelling and OMM discontinuities in other primary B-cell malignancies, including mantle cell, follicular and marginal zone lymphoma cells but not in several cell lines studied. Thus, we describe a new paradigm of apoptosis in primary B-cell malignancies, whereby targeting of BCL2 results in all the classical features of apoptosis together with OMM rupture independent of caspase activation. This mechanism may be far more prevalent than hitherto recognized due to the failure of most methods, used to measure apoptosis, to recognize such a mechanism.

Cell Death and Differentiation (2008) 15, 820-830; doi:10.1038/cdd.2008.25; published online 29 February 2008

Apoptosis occurs following either triggering of cell surface death receptors (the extrinsic pathway) or perturbation of mitochondria (the intrinsic pathway). In the intrinsic pathway, release of cytochrome $c$ and other proapoptotic proteins from mitochondria to cytosol is described as the most critical event for apoptosis induction. Members of the BCL2 family are important regulators of cytochrome $c$ release and apoptosis and they are associated with resistance of many tumors to chemotherapy. The BCL2 family comprises antiapoptotic members, such as BCL2, MCL1 and BCL- $\mathrm{X}_{\mathrm{L}}$, multi-domain proapoptotic members, such as BAX and BAK, and proapoptotic $\mathrm{BH}$-only proteins, including BAD, BIM and PUMA. ${ }^{1,2}$ On receipt of a death signal, $B A X$ and $B A K$ can form oligomers in the outer mitochondrial membrane (OMM), leading to its permeabilization, release of cytochrome $c$ and caspase activation, whereas antiapoptotic BCL2 members prevent this release by blocking activation of $\mathrm{BAX}$ and $\mathrm{BAK}$. $\mathrm{BH} 3-$ only proteins, which act upstream of BAX and BAK, are critical for cell death initiation, and their activity is tightly controlled by diverse transcriptional and post-translational mechanisms. ${ }^{1,2}$ BH3-only proteins selectively bind into the hydrophobic groove of antiapoptotic BCL2 family proteins leading to BAX/BAK activation and mitochondrial outer membrane permeabilization (MOMP). ${ }^{1,3-5}$ Currently there are two major models proposed to account for loss of cytochrome $c$ from the mitochondrial intermembrane space. The more favored model involves $B A X$ and/or BAK oligomerization with formation of channels in the OMM leading to MOMP. In contrast, formation of channels across the inner mitochondrial membrane (IMM) causes the equilibration of ions between the mitochondrial matrix and cytoplasm resulting in matrix swelling and IMM unfolding. This results in OMM rupture due to the larger surface area of the IMM compared with the OMM. ${ }^{6-8}$ The IMM has an intrinsically low permeability to ions and solutes, which allows the build up of a proton gradient across the IMM, that is required for oxidative phosphorylation. Owing to the highprotein content of the mitochondrial matrix, the osmotic balance between mitochondrial matrix and cytosol requires tight regulation to prevent water influx. The rate of water influx into mitochondria is mainly regulated by the $\mathrm{K}^{+}$cycle. ${ }^{9}$

The process of mitochondrial inner membrane permeabilization (MIMP) is often associated with permeability transition pore (PTP) opening. ${ }^{10-13}$ The PTP is a multi-protein complex which as yet is poorly defined at the molecular level. Previously the PTP was thought to comprise the adenosine nucleotide translocator and cyclophilin D on the IMM complexed with voltage dependent anion channel and the peripheral benzodiazepine receptor on the OMM. $6,7,14,15$ However, recent data using knockout animals suggests that only cyclophilin $D$ is a bona fide regulatory component. ${ }^{16}$ Several interactions of the components of the PTP with BCL2 proteins have been described; however, the role if any of BCL2 in regulation of MIMP is controversial. ${ }^{7}$ An alternative, less studied, model proposes that aggregation of mitochondrial membrane proteins induced by various stresses forms the PTP and initially chaperone-like molecules block this

${ }^{1}$ MRC Toxicology Unit, University of Leicester, Leicester, UK

*Corresponding author: GM Cohen, MRC Toxicology Unit, University of Leicester, Hodgkin Building, Lancaster Road, PO Box 138, Leicester LE1 9HN, UK. Tel: + 44116 2525601; Fax: + 44116 2525616; E-mail: gmc2 @le.ac.uk

Keywords: ABT-737; rupture of outer mitochondrial membrane; BCL2; cytochrome $c$ release; CLL

Abbreviations: CLL, chronic lymphocytic leukemia; IMM, inner mitochondrial membrane; OMM, outer mitochondrial membrane; MIMP, mitochondrial inner membrane permeabilization; MOMP, mitochondrial outer membrane permeabilization; PTP, permeability transition pore; $\Psi \mathrm{m}$, mitochondrial membrane potential

Received 19.10.07; revised 21.1.08; accepted 22.1.08; Edited by B Zhivotovsky; published online 29.2.08 
aggregation until a threshold is reached which then results in opening of unregulated pores. ${ }^{17}$ In addition to the PTP, several ion channels and aquaporins located in the IMM have been implicated in mitochondrial swelling upon apoptotic stimuli (reviewed in Lee and Thevenod ${ }^{9}$ ).

Chronic lymphocytic leukemia (CLL) is one of the most common forms of leukemia in adults with about 12000 new cases identified annually in Europe. Some patients survive many years without therapy whereas others die rapidly despite intensive therapy. In this study, we targeted BCL2 in CLL using ABT-737, a newly designed inhibitor that binds BCL2, BCL- $X_{L}$ and BCL-w with high affinity $\left(K_{i} \leqslant 1 \mathrm{nM}\right) .{ }^{18,19}$ CLL is a disease of failed apoptosis with high levels of BCL2 and high BCL2/BAX ratios. ${ }^{20}$ By inhibiting BCL2, we found that activation of $B A X$ and BAK not only results in MOMP but also contributes to MIMP, swelling of mitochondria and OMM rupture.

\section{Results}

ABT-737 induces a rapid concentration-dependent apoptosis of CLL cells. Peripheral blood samples were obtained from CLL patients. Lymphocytes were isolated and exposed to the BCL2-antagonist, ABT-737. ABT-737 caused an extensive and rapid apoptosis in CLL cells with an $\mathrm{EC}_{50}$ of
$7 \mathrm{nM}$ at $4 \mathrm{~h}$ (Figure 1a) in agreement with previous observations. ${ }^{18,21}$ An enantiomer of ABT-737 (with the opposite configuration of the dimethylaminoethyl group), with both reduced activity and binding affinity to BCL2, ${ }^{18}$ failed to induce apoptosis at $4 \mathrm{~h}$ and only caused a slight increase in apoptosis after $20 \mathrm{~h}$ (Figure 1a). Exposure of CLL cells to ABT-737 resulted in a time- and concentrationdependent loss of mitochondrial membrane potential $(\Psi \mathrm{m})$ (Figure 1b) and release of cytochrome $c$ (Figure 1c). Notably, release of cytochrome $c$ into the cytosol was rapid and complete within $2 \mathrm{~h}$ of exposure to $\mathrm{ABT}-737$. In addition OPA1, an IMM protein, was partially released from mitochondria at a similar time as cytochrome $c$ but the release of OPA1 was incomplete with significant amounts retained in the mitochondria (Figure 1c). Release of mitochondrial cytochrome $c$ results in activation of the Apaf-1 apoptosome followed by activation of the initiator caspase- 9 and subsequent activation of effector caspases, such as caspase-3, resulting in the cleavage of caspase substrates, like poly(ADP-ribose) polymerase (PARP) (reviewed in Bratton et $a^{22}$ ). Compatible with this model, we observed a time-dependent processing of caspase-9, -3 and -7 accompanied by PARP cleavage to a characteristic $\sim 85-k D a$ fragment (Figure 1d). Furthermore, ABT-737induced apoptosis was inhibited in a concentrationdependent manner by the broad-spectrum caspase
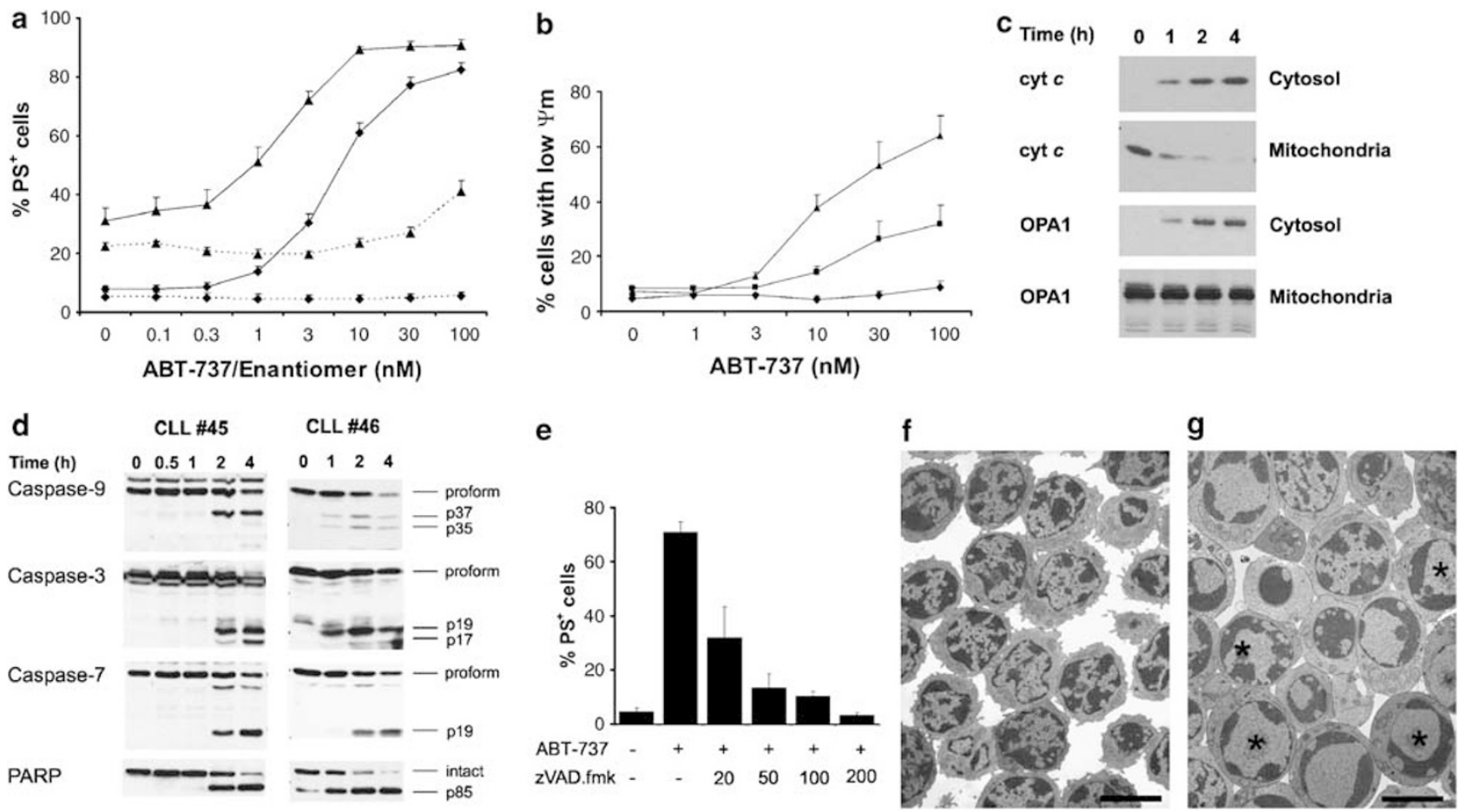

Figure 1 ABT-737 induces rapid caspase-dependent apoptosis in CLL cells. (a) CLL cells were exposed to ABT-737 (0.1-100 nM) (solid lines) or its inactive enantiomer (dotted lines) for $4 \mathrm{~h}(\bullet)$ or $20 \mathrm{~h}(\boldsymbol{\Delta})$ and apoptosis assessed by PS externalization. Data are the mean + S.E.M. $(n=10)$. (b) CLL cells were exposed to ABT-737 for 1 ( $\bullet$ ), $2(\boldsymbol{\square})$ or $4 \mathrm{~h}(\boldsymbol{\Delta})$ and $\Psi \mathrm{m}$ assessed. Data are the mean + S.E.M. $(n=10)$. (c) Cells were exposed to ABT-737 $(10 \mathrm{nM})$ and at the indicated times cytosol and mitochondrial fractions were analyzed by western blotting for cytochrome $c$ (cyt $c$ ) and OPA1. (d) CLL cells from two patients (no. 45 and no. 46) were exposed to ABT-737 (10 nM) and analyzed for caspase processing and PARP cleavage. (e) Cells were exposed to ABT-737 (10 nM) for $4 \mathrm{~h}$ either alone or with the indicated concentration of z-VAD.fmk ( $\mu \mathrm{M})$ and apoptosis assessed by PS externalization. Data are the mean \pm S.E.M. $(n=5)$. (f) Untreated CLL cells were characterized by rounded nuclei containing moderately condensed heterochromatin which extended, as poorly defined projections, throughout the nucleoplasm (bar $=5 \mu \mathrm{m})$. (g) Cells exposed to ABT-737 (10 $\mathrm{nM}$ ) for $2 \mathrm{~h}$ showed accumulations of condensed heterochromatin against the inner membrane of the nuclear envelope and segregation of the nucleolus $(*)(\mathrm{bar}=5 \mu \mathrm{m})$ 
inhibitor, z-VAD.fmk (Figure 1e). Within $2 \mathrm{~h}$ of exposure to ABT-737, the characteristic ultrastructure of control CLL cells (Figure 1f) changed to exhibit most of the characteristic ultrastructural features of apoptosis, in particular, marked chromatin condensation and nucleolar segregation (Figure 1g).

Apoptosis via the intrinsic pathway is usually initiated by activation of BAX and/or BAK. Upon exposure to ABT-737, a rapid conformational change of both $B A K$ and $B A X$ was observed in CLL cells within $1 \mathrm{~h}$ (Figure 2a). Transfection with BAX-GFP revealed that BAX-GFP was cytoplasmic in untreated CLL cells, whereas following exposure to ABT737 it redistributed forming clusters of BAX associated with the mitochondria (Figure $2 \mathrm{~b}$ and Supplementary Video 1). Oligomerization of both BAX and BAK was observed within $1 \mathrm{~h}$ in mitochondrial fractions from ABT-737-treated but not untreated control CLL cells (Figure 2c, lanes 1-2) and this oligomerization was largely unaffected by z-VAD.fmk (Figure 2c, lanes 3-4). Therefore, we conclude that targeting of BCL2 by $A B T-737$ results in rapid activation of $B A X$ and $B A K$ upstream of caspase activation. These data are consistent with ABT-737 inducing rapid apoptosis in primary CLL cells by oligomerization of BAX/BAK and release of cytochrome $c$, thus resulting in a range of biochemical and ultrastructural changes associated with the induction of classical apoptosis via the intrinsic pathway.

ABT-737 induces rupture of the OMM. The cytoplasm of CLL cells, which extended as a thin rim around the nucleus, contained a few mitochondria with well-defined transverse cristae (Figure 3a). In addition to the classical nuclear hallmarks of apoptosis (Figure 1g), ABT-737 induced striking changes in mitochondria, involving swelling of the mitochondrial matrix, focal loss of matrix density and extensive discontinuities of the OMM (Figure 3b). Following exposure to ABT-737 (10 nM) for $2 \mathrm{~h}, \sim 64 \%$ of cell profiles contained severely swollen mitochondria and $\sim 29 \%$ exhibited OMM discontinuities, which after $4 \mathrm{~h}$ increased to 79 and $61 \%$, respectively. In control untreated cells, $\sim 2 \%$ of the cell profiles exhibited swollen mitochondria and no OMM breaks were observed. As these counts were from $\sim 80 \mathrm{~nm}$ sections, they were most probably underestimates of the incidence of changes in whole cells. These changes occurred early, as in some cells they clearly preceded chromatin condensation. The mitochondrial swelling was not uniform throughout the cell population or even within individual cells, and was often restricted to only part of the organelle. On the basis of the previous findings ${ }^{6-8}$ discontinuities of the OMM were consistent with matrix swelling due to MIMP, such as would occur via opening of the PTP. This would lead to unfolding of the IMM, so causing OMM rupture due to the larger surface area of the IMM, compared with the OMM. z-VAD.fmk completely inhibited the nuclear changes induced by ABT-737 but not the matrix swelling or the OMM discontinuities (Figure $3 \mathrm{c}$ and unpublished data). Following pre-treatment with z-VAD.fmk, exposure to ABT-737 for $4 \mathrm{~h}$ induced severely swollen mitochondria in $\sim 89 \%$ and OMM discontinuities in $\sim 77 \%$ of cell profiles. These results demonstrate that OMM discontinuities are an early upstream caspase-independent event in ABT-737-induced cell death.

To investigate whether the mitochondrial swelling was associated with the drop of $\Psi \mathrm{m}$, CLL cells were exposed to ABT-737 for $2 \mathrm{~h}$ and then sorted by flow cytometry into cells with high and low $\Psi \mathrm{m}$, as assessed by TMRE uptake. Ultrastructural examination of the sorted cells revealed that cells with high/intact $\Psi \mathrm{m}$ showed no chromatin condensation and no matrix swelling or discontinuities of the OMM (Figure 3d). However, cells with low $\Psi \mathrm{m}$ (65\% of sample) exhibited nuclear chromatin condensation, swollen mitochondria a

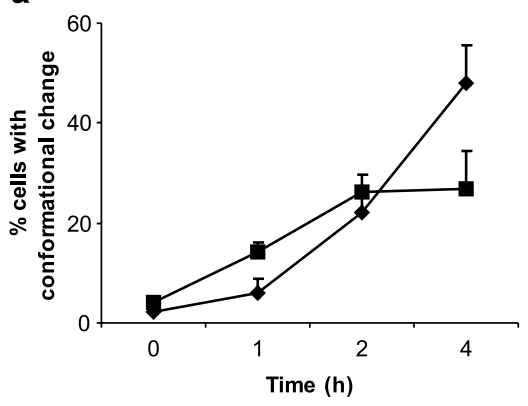

b
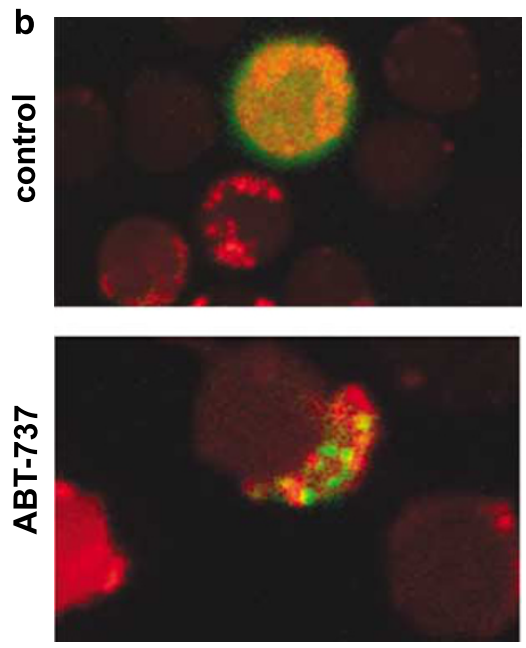

C Time (h) z-VAD.fmk $\begin{array}{llll}0 & 1 & 2 & 2\end{array}$
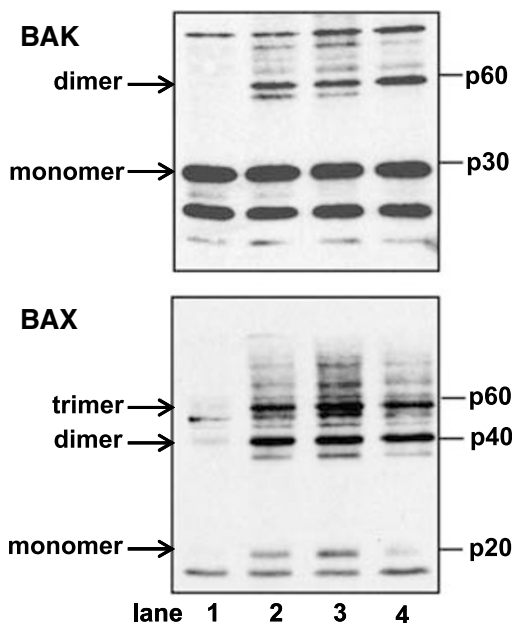

Figure 2 ABT-737 induces BAX/BAK activation in CLL cells. (a) CLL cells were exposed to ABT-737 (10 nM) for 1-4 h and the conformational change of BAX ( $\downarrow$ ) or BAK (西) was detected using conformational specific antibodies. Data are the mean + S.E.M. $(n=10)$. (b) Cells were transfected with pEGFP-C1-BAX for $12 \mathrm{~h}$ (upper panel), stained with $0.2 \mu \mathrm{M}$ Mitotracker-orange and exposed to ABT-737 (10 nM) for $2 \mathrm{~h}$ (lower panel). Images were acquired by live cell imaging. Untreated control image (upper panel) was taken as a stack to visualize cytoplasmic green fluorescence while ABT-737 treated picture (lower panel) was taken as a single layer. (c) Cells were exposed to ABT-737 (10 nM) with or without z-VAD.fmk $(20 \mu \mathrm{M})$ and BAX/BAK oligomerization on mitochondrial fractions assessed 

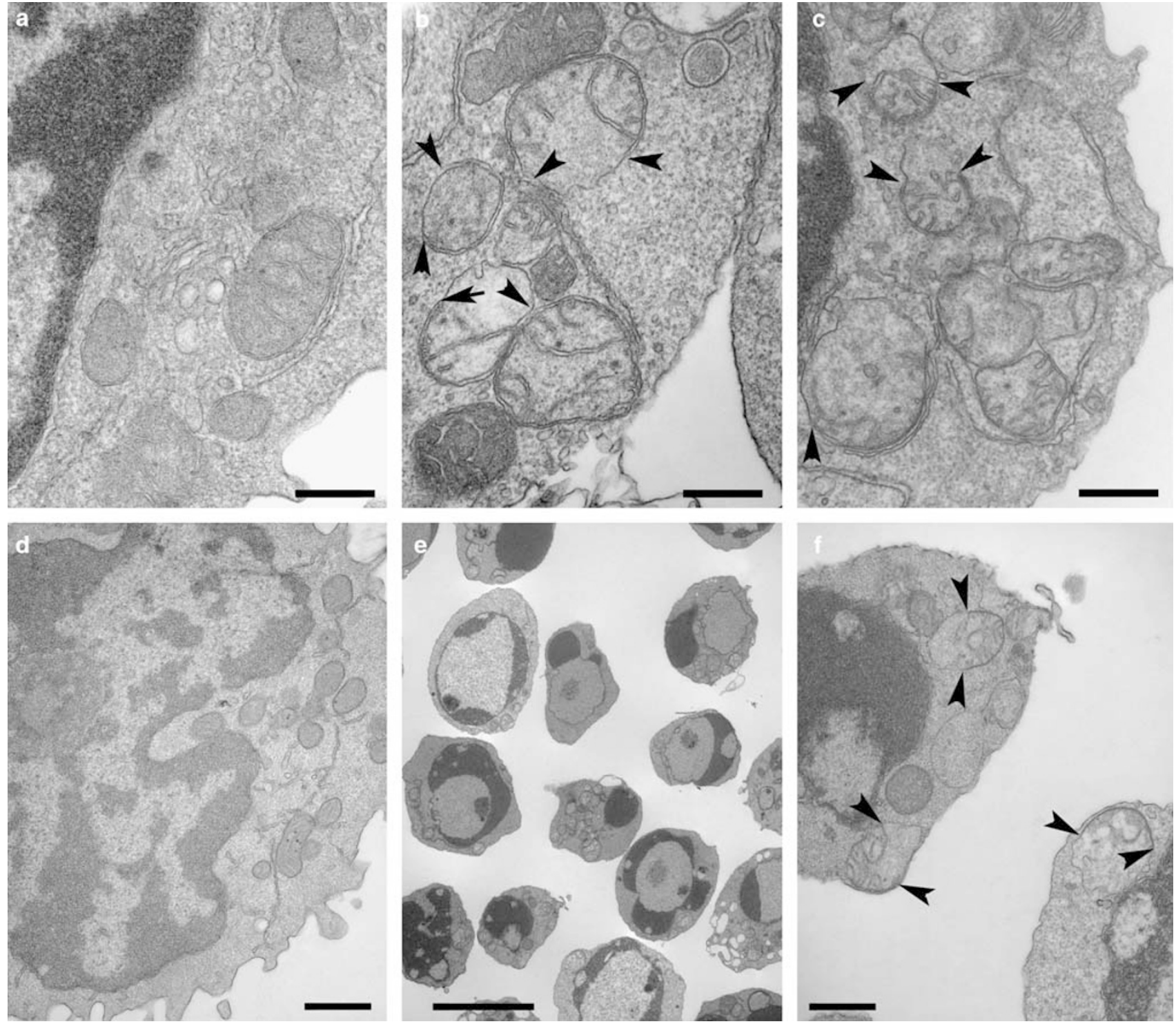

Figure 3 ABT-737 induces rupture of the OMM of CLL cells. (a) The cytoplasm of untreated CLL cells contained a few mitochondria, with well-defined transverse cristae (bar $=0.5 \mu \mathrm{m})$. (b) Many mitochondria in CLL cells exposed to ABT-737 $(10 \mathrm{nM})$ for $2 \mathrm{~h}$ showed various degrees of matrix swelling and focal reductions in the electron density of the contents. These changes were often associated with extensive discontinuities in the OMM (arrowheads) (bar $=0.5 \mu \mathrm{m})$. (c) Mitochondria of cells exposed to ABT-737 $(10 \mathrm{nM})$, in the presence of $\mathrm{z}-\mathrm{VAD}$.fmk $(200 \mu \mathrm{M})$ for $4 \mathrm{~h}$, maintained a normal nuclear morphology, but many mitochondria were swollen and exhibited OMM discontinuities (arrowheads) (bar $=0.5 \mu \mathrm{m})$. (d-f) CLL cells were exposed to ABT-737 $(10 \mathrm{nM})$ for $2 \mathrm{~h}$ and were then sorted by a FACS into cells with high or low $\Psi \mathrm{m}$ using TMRE as described in the Materials and Methods section. (d) Cells with high $\Psi \mathrm{m}$ showed normal nuclear and mitochondrial ultrastructure (bar $=1 \mu \mathrm{m})$. (e and f) Cells with low $\Psi \mathrm{m}$ showed condensed chromatin and mitochondrial matrix swelling and rupture of the OMM (arrowheads) (In e and $\mathbf{f}$, the bar $=5$ and $1 \mu \mathrm{m}$, respectively)

and OMM discontinuities (Figure $3 e$ and $\mathrm{f}$ ), indicating that mitochondrial swelling and OMM discontinuities were associated with loss of $\Psi \mathrm{m}$ and apoptosis. Taken together, our data describe for the first time that targeting of BCL2 results in two distinctive morphological changes, one involving classic nuclear changes clearly associated with apoptosis and the other involving mitochondrial matrix swelling and OMM discontinuities, ultrastructural changes generally associated with necrosis but not with apoptosis. ${ }^{23}$

BAX and BAK localize at mitochondrial breakpoints. Interestingly, following $A B T-737$ treatment, using conformationally active antibodies both BAX (Figure 4a and b) and BAK (Figure 4c) were clearly localized in clusters at those mitochondria showing OMM discontinuities, whereas mitochondria from untreated cells were unlabeled (data not shown). The localization of BAX in distinct mitochondrially associated clusters was consistent with the confocal microscopy data (Figure $2 b$ ). The close proximity of BAX and BAK with the OMM break points highlights the possibility that activated BAX and BAK might not only induce MOMP but also contribute to OMM rupture.

ABT-737 induces MIMP. Our initial data showing oligomerization of BAX/BAK, release of cytochrome $c$ and caspase activation (Figures 1 and 2 ) are clearly compatible 

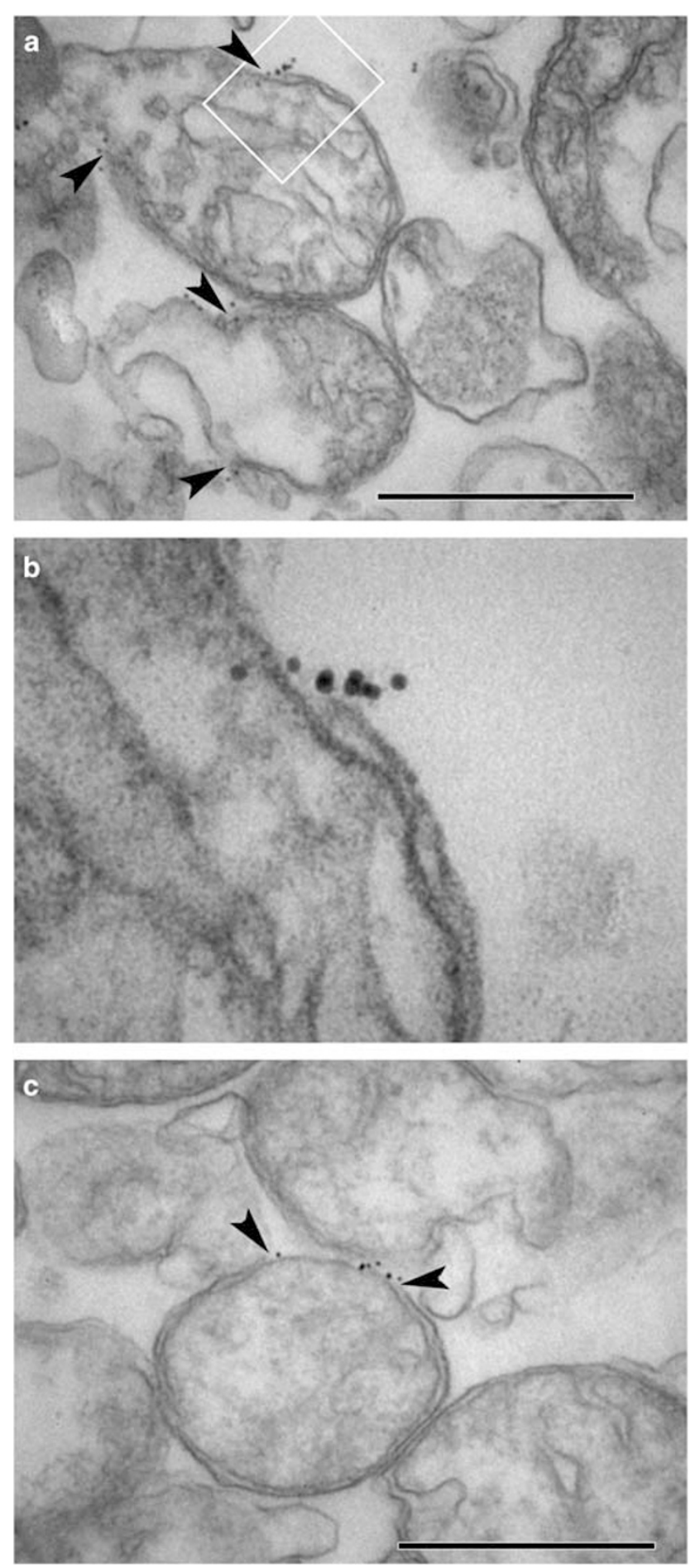

Figure 4 BAX and BAK localize to ABT-737-induced break points on the OMM. (a-c) CLL cells were exposed to ABT-737 $(10 \mathrm{nM})$ for $2 \mathrm{~h}$. Mitochondrial fractions were incubated with either (a and $\mathbf{b})$ anti-BAX or $(\mathbf{c})$ anti-BAK $A b$ and labeled with anti-mouse $\operatorname{lgG}$ gold $(10 \mathrm{~nm})$. Labeling was often associated with breaks in the OMM (arrowheads). The boxed area in (a) is magnified in $(\mathbf{b})(\mathrm{bars}=0.5 \mu \mathrm{m})$

with MOMP occurring following formation of BAX/BAK channels in the OMM. However, the caspase-independent ABT-737-induced mitochondrial matrix swelling and OMM rupture are consistent with MIMP. To investigate directly whether ABT-737 induced MIMP, we utilized a method that relies on loading cells with calcein acetoxymethyl ester (calcein.AM), a fluorescent probe, together with its quencher, cobalt. $^{6,24,25}$ Intracellular esterases cleave the probe, resulting in the trapping of calcein in all cellular compartments including mitochondria. The calcein fluorescence is quenched by cobalt in all cellular compartments except mitochondria, which exclude cobalt due to the impermeability of the IMM to this ion. Thus distinct punctate calcein fluorescence coincident with mitochondria is observed in cells with an intact IMM..$^{6,24,25}$ Compatible with this model, the majority of control CLL cells showed discrete calcein labeling of mitochondria. Some cytosolic background staining was observed, which could be due to inadequate quenching by the cobalt (Figure 5a). Exposure of CLL cells to ABT-737 $(10 \mathrm{nM})$ for $2 \mathrm{~h}$ resulted in loss of the discrete mitochondrial labeling, compatible with the hypothesis that ABT-737 induced MIMP (Figure $5 b$ and $c$ ). Since we were primarily interested in early upstream events induced by ABT-737 and not in caspase-mediated processes these experiments were performed in the presence of z-VAD.fmk. To validate further the calcein/cobalt method for assessment of MIMP, CLL cells were exposed to $t$-butyl hydroperoxide (tBH), a known inducer of PTP opening. ${ }^{24}$ Similar to ABT737, exposure to $\mathrm{tBH}$ also resulted in loss of punctate mitochondrial calcein staining compatible with MIMP. However, in contrast to $\mathrm{ABT}-737, \mathrm{tBH}$ did not induce mitochondrial matrix swelling, OMM rupture or apoptosis (data not shown).

Addition of cyclosporin A, an inhibitor of PTP opening, did not inhibit ABT-737-induced loss of mitochondrial calcein staining, indicating that ABT-737 induces MIMP independent of PTP opening. Furthermore, cyclosporin A did not inhibit ABT-737-induced mitochondrial swelling, OMM rupture, cytochrome $c$ release, drop of $\Psi \mathrm{m}$ or apoptosis as assessed by phosphatidylserine (PS) externalization (Supplementary Figure 1).

PTP opening is highly sensitive to $\mathrm{Ca}^{2+}$ or pro-oxidants. ${ }^{6,7}$ Following exposure of CLL cells to ABT-737, we could not detect any increase in reactive oxygen species nor could a number of anti-oxidants confer protection (data not shown). Taken together these results indicate that ABT-737 induces MIMP independent of the classical PTP. Furthermore, our data suggest that ABT-737-induced MIMP is caspase independent and an early upstream event induced by ABT737.

Discontinuities in the OMM are a characteristic of rapid apoptosis in CLL cells. The matrix swelling and OMM rupture induced by $A B T-737$ were surprising as they are not considered a general feature of apoptotic cells. In previous studies, in CLL cells with various apoptotic stimuli, we observed nuclear changes characteristic of apoptosis without marked OMM rupture. ${ }^{26,27}$ However, these agents induced apoptosis more slowly (8-24 h) than ABT-737. To ascertain if the OMM discontinuities were specific to ABT-737 or could be induced by other stimuli that induce rapid apoptosis, CLL cells were exposed to 2-naphthylvinyl ketone, a Jak3 inhibitor, ${ }^{28}$ which activates the intrinsic pathway (unpublished data). 2-Naphthylvinyl ketone induced rapid 

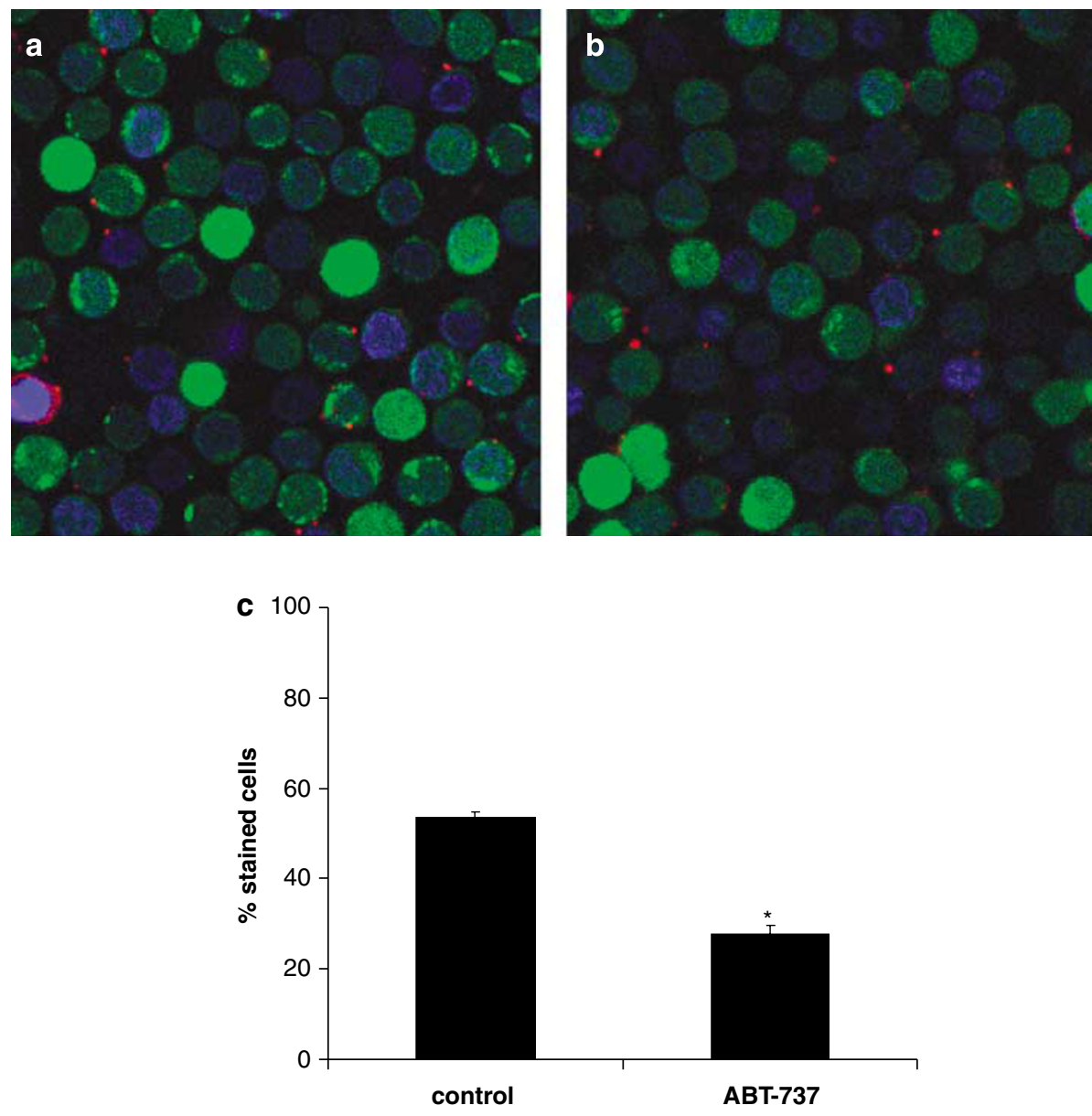

Figure 5 ABT-737 induces MIMP. (a) Control CLL cells $\left(5 \times 10^{6}\right.$ per ml) were incubated at $37^{\circ} \mathrm{C}$ for 30 min with calcein. $\mathrm{AM}(100 \mathrm{nM})$ and $\mathrm{CoCl} 2(1 \mathrm{mM})$ and then incubated in fresh medium without calcein.AM and $\mathrm{CoCl}_{2}$. Nuclei were stained with Hoechst 33342 (blue) and PS externalization detected (red) using Annexin V-APC conjugate and cells were examined using a Zeiss LSM 510 laser scanning confocal microscope. (b) CLL cells were stained with calcein. $\mathrm{AM}$ and $\mathrm{CoCl}{ }_{2}$ as in (a), exposed to Z-VAD.fmk $(200 \mu \mathrm{M})$ for $30 \mathrm{~min}$ and then exposed to ABT-737 $(10 \mathrm{nM})$ for $2 \mathrm{~h}$. (c) Upon treatment the number of cells with discrete labeling of mitochondria were scored in a blinded fashion. The quantification was done on cells from three patients and for each patient, five fields were counted with 300 cells per field. The results are expressed as the mean + S.E.M. $P$-values were determined using unpaired Student's $t$-test $\left({ }^{*} P<0.05\right)$

apoptosis in CLL cells, with $57 \%$ apoptotic cells after $4 \mathrm{~h}$ exposure, and this was accompanied by nuclear condensation, mitochondrial matrix swelling and OMM discontinuities (Figure 6a). 2-Naphthylvinyl ketone also induced PS externalization, loss of $\Psi \mathrm{m}$ and a rapid conformational change of BAX and BAK accompanied by complete release of mitochondrial cytochrome $c$ and a partial release of OPA1 (Figure $6 b$ and $c$ ). Thus, rapid induction of apoptosis in CLL cells, by agents other than ABT-737, was associated with classical apoptotic hallmarks, such as BAX/ BAK activation and chromatin condensation, as well as marked mitochondrial matrix swelling and OMM discontinuities.

ABT-737 induces OMM discontinuities in primary malignant $B$ cells but not in several cell lines. To ascertain whether ABT-737-induced apoptosis was accompanied by similar OMM discontinuities in other primary cells, we examined its effects on different B-cell malignancies. Nanomolar concentrations of ABT-737 caused a rapid concentration-dependent induction of apoptosis in primary mantle cell, marginal zone and follicular lymphoma cells (Figure 7a). Exposure of primary mantle cell lymphoma cells to ABT-737 was also accompanied by mitochondrial matrix swelling and OMM rupture (Figure $7 b$ ). Similar matrix swelling and OMM discontinuities were observed in both primary follicular and marginal zone lymphoma cells exposed to ABT-737 (data not shown) indicating that this is a common phenotype of primary human malignant $B$ cells.

Next we wished to examine if similar matrix swelling and OMM breaks were observed in various cell lines. To obtain relatively rapid apoptosis in most cell lines studied to date, it was necessary to expose them to micromolar concentrations of ABT-737 compared with the nanomolar concentrations required to induce apoptosis in primary B-cell malignancies. ABT-737 induced rapid apoptosis in several human cancer cell lines, including Jurkat cells, a T-cell lymphoma line, and Z138 cells, a mantle cell lymphoma line. Induction of rapid apoptosis in Jurkat cells by ABT-737 $(3 \mu \mathrm{M})$ was accompanied by marked nuclear changes characterized by chromatin condensation and nuclear fragmentation (Figure 7c). However, the rapid induction of apoptosis in Jurkat cells was not 
a

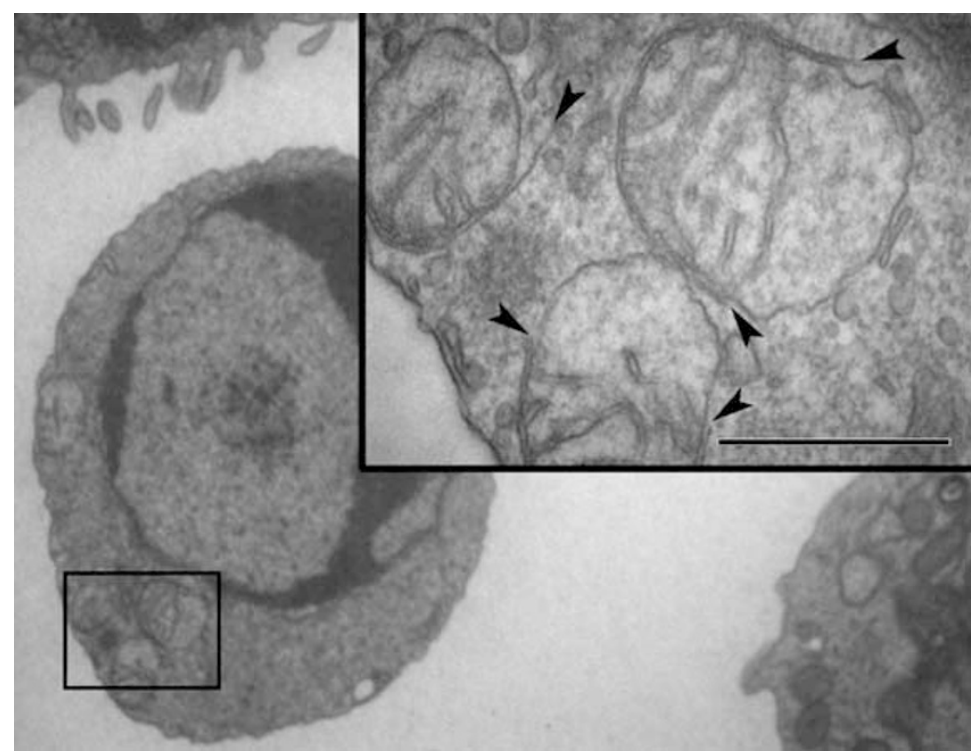

b

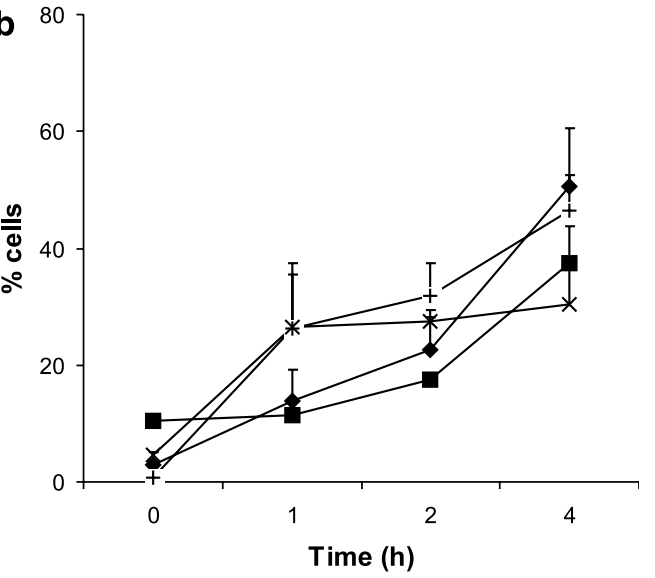

C

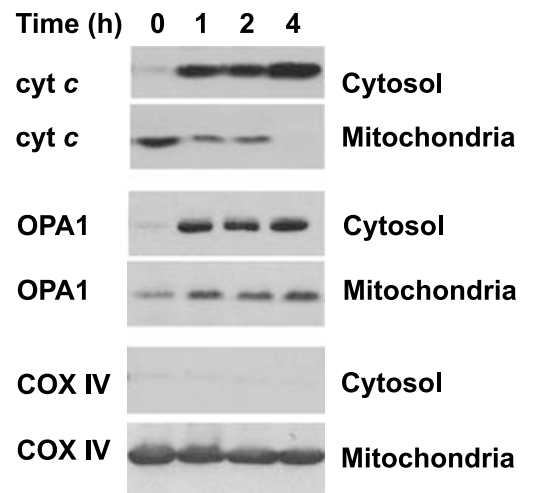

Figure 6 OMM discontinuities are a common feature of rapid apoptosis in CLL cells. (a) CLL cells, exposed to 2-naphthylvinyl ketone (10 $\mu \mathrm{M})$ for $4 \mathrm{~h}$, showed condensed chromatin characteristic of apoptosis together with matrix swelling and OMM discontinuities (arrowheads) (bar $=0.5 \mu \mathrm{m})$. (b) CLL cells were exposed to 2-naphthylvinyl ketone $(10 \mu \mathrm{M})$ for $0-4 \mathrm{~h}$ and apoptosis assessed by PS externalization $(\checkmark)$, data are the mean + S.E.M. $(n=9)$, loss of $\Psi \mathrm{m}(\boldsymbol{\square})(n=5)$, or the conformational change in $\mathrm{BAX}(+)$ and $\mathrm{BAK}(\times)$ was assessed $(n=3)$. (c) Following exposure to 2-naphthylvinyl ketone $(10 \mu \mathrm{M})$ for the indicated times, cytosol and mitochondria were analyzed by western blotting for cytochrome $c$ (cyt $c$ ) and OPA1. The IMM protein, cytochrome $c$ oxidase IV (COX IV), was used as a fractionation control

accompanied by either mitochondrial swelling or OMM rupture but rather by the appearance of ultracondensed mitochondria (Figure 7c), which were not present in untreated Jurkat cells (data not shown). Furthermore, examination of Jurkat cells at earlier times following exposure to ABT-737 did not reveal any evidence that either matrix swelling or OMM breaks was a significant feature of apoptotic Jurkat cells. Similarly, extensive apoptosis was induced in Z138 cells after exposure for $4 \mathrm{~h}$ to ABT-737 ( $1 \mu \mathrm{M})$. Although ultrastructural examination of these cells revealed extensive chromatin condensation accompanied by the formation of both ultracondensed and swollen mitochondria, there was no significant rupture of the OMM (data not shown). In conclusion, our data demonstrate that rapid apoptosis induced by ABT-737 in primary malignant $B$ cells is accompanied by ultrastructural changes of mitochondria clearly distinct from those induced in cell lines.

\section{Discussion}

ABT-737, developed using NMR-based screening and structure based design, binds with high affinity into the hydrophobic groove of $B C L 2, B C L-X_{L}$ and $B C L-w$, thereby displacing $B H 3-$ containing proteins which then lead either directly or indirectly to the activation of BAX and BAK, cytochrome $c$ release and caspase activation. ${ }^{1,18,29}$ ABT-737 acts specifically through inhibition of antiapoptotic BCL2 family members. To the best of our knowledge no nonspecific actions of ABT-737 have yet been described. Thus, it is reasonable to assume that most if not all of the effects observed in the present study result from the ability of ABT-737 to inhibit BCL2 in CLL cells as freshly isolated CLL cells contain little if any BCL- $X_{L}$ and ABT-737 does not inhibit MCL1.

Two remarkable findings have been revealed in this study, namely a novel paradigm of apoptosis and an exquisite sensitivity of primary CLL cells to ABT-737. ABT-737 causes an extremely rapid induction of apoptosis in CLL cells, accompanied by a host of biochemical and ultrastructural changes characteristic of apoptosis. These biochemical changes include activation and oligomerization of BAX/BAK, release of cytochrome $c$, loss of $\Psi \mathrm{m}$, activation of both caspase-9 and caspase-3, cleavage of PARP and externalization of PS (Figures 1 and 2). The ultrastructural changes include extensive chromatin condensation and nucleolar disintegration (Figure 1g). All these biochemical and ultrastructural changes have invariably been associated with the induction of classical apoptosis via the intrinsic pathway. However, in addition to all these changes, ultrastructural examination revealed the presence of mitochondrial matrix 

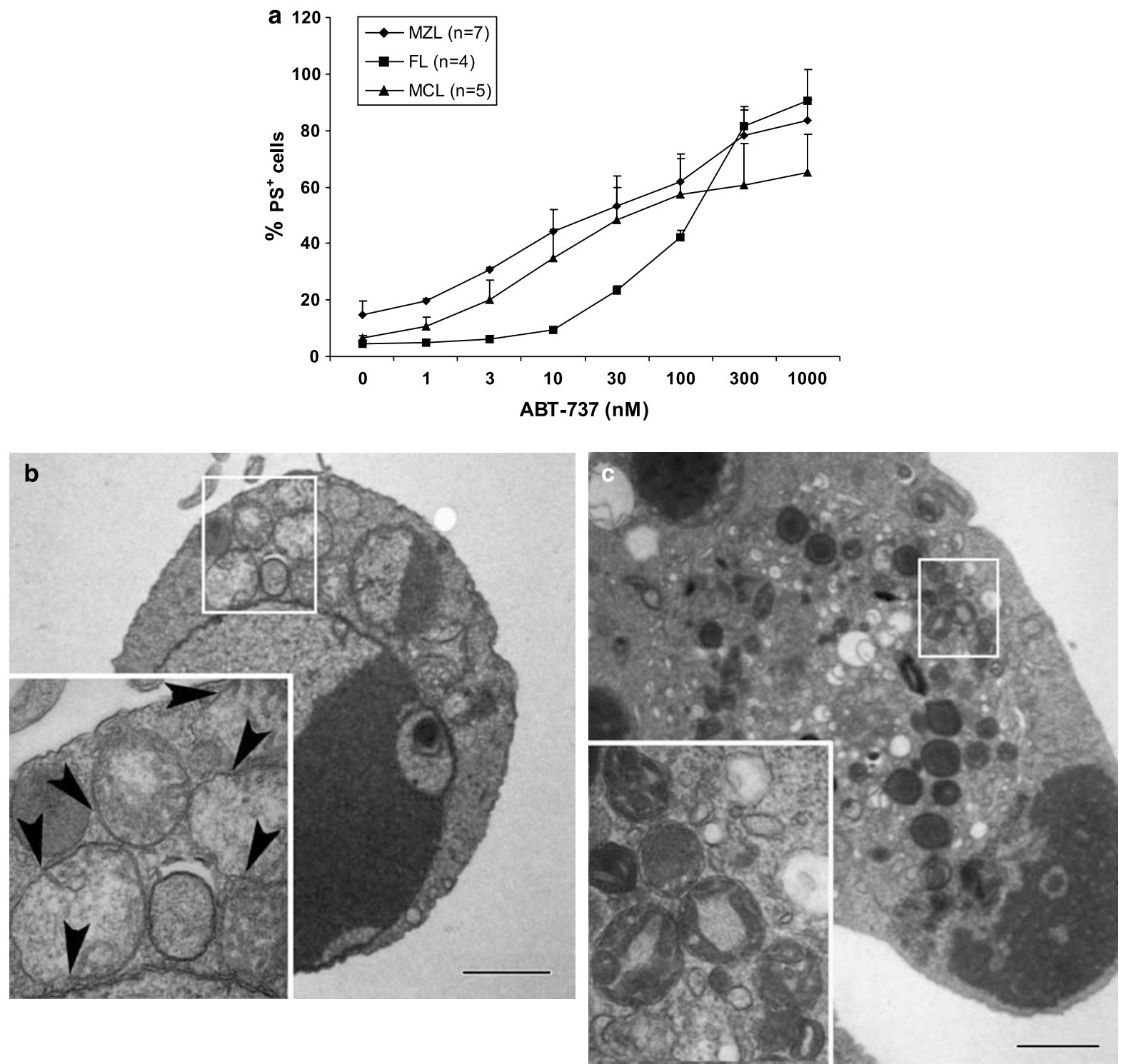

Figure 7 ABT-737 induces OMM breaks in primary malignant B cells but not in some cell lines. (a) Primary mantle cell (MCL), marginal zone (MZL) and follicular (FL) lymphoma cells from patients were exposed to a range of ABT-737 concentrations for $4 \mathrm{~h}$ and apoptosis assessed by PS externalization. (b) Freshly isolated mantle cell lymphoma cells were exposed to ABT-737 $(30 \mathrm{nM})$ for $2 \mathrm{~h}$. Rapid apoptosis was induced and ultrastructural examination revealed the presence of chromatin condensation, nuclear fragmentation accompanied by mitochondrial swelling and rupture of the OMM (arrowheads) as shown in the magnified view. (c) Jurkat cells were exposed to ABT-737 $(3 \mu \mathrm{M})$ for $6 \mathrm{~h}$, which induced $56 \%$ apoptosis, assessed by PS externalization. Ultrastructural examination revealed nuclear changes, characteristic of classical apoptosis, including the presence of condensed chromatin and fragmented nuclei. Strikingly, ABT-737 induced the formation of ultracondensed mitochondria in the absence of breaks in the OMM. A similar ultrastructure of ultracondensed but not swollen mitochondria was observed at all time points studied (Bars $=1 \mu \mathrm{m})$

swelling and OMM breaks (Figure 3), features much more commonly associated with necrosis than apoptosis. Discontinuities of the OMM are consistent with matrix swelling due to MIMP and unfolding of the IMM leading to OMM rupture. $^{6-8}$ Thus, our studies establish a novel paradigm of apoptosis whereby cells exhibit all the characteristic biochemical and ultrastructural changes commonly associated with classical apoptosis as well as matrix swelling and OMM breaks.

How common are OMM breaks as a feature of apoptotic cells? Although some previous studies on the induction of apoptosis have noted OMM discontinuities, their extent and incidence have generally been quite low. ${ }^{8}$ To our knowledge, only three published studies using bona fide apoptotic stimuli have shown a high incidence of matrix swelling and OMM breaks. Two of these studies were in hepatocytes in vivo when extensive apoptosis was induced within $5 \mathrm{~h}^{30,31}$ The other report ascribed the induction of such changes, in cell lines induced to undergo apoptosis by various apoptotic stimuli, to PTP opening. ${ }^{32}$ Swollen mitochondria and OMM rupture commonly occur late in the process of cell death, including apoptotic cells undergoing secondary necrosis but are comparatively rare at the onset of apoptosis. The rarity of such changes in apoptotic cells may be due to the induction of 
apoptosis generally being a slow stochastic process, whereas the rapid synchronized induction of apoptosis by ABT-737 in CLL cells may have facilitated the recognition of cells with OMM breaks.

Using the calcein/cobalt method, it was clear that ABT-737 induced rapid MIMP, which has been associated with PTP opening during cell death (Figure 5). To determine whether MIMP induced by ABT-737 involved PTP opening we used cyclosporin A, a classical PTP inhibitor. Cyclosporin A did not inhibit loss of mitochondrial calcein staining, mitochondrial swelling or OMM rupture. Since sensitivity to cyclosporin A is one of the defining characteristics of the PTP, ABT-737 is likely to induce MIMP without involvement of classical PTP opening. MIMP, mitochondrial swelling and OMM rupture were most likely linked to a BCL2 function that is inhibited by ABT-737 as no swelling was observed upon treatment with the inactive enantiomer of ABT-737 (unpublished data). Mitochondrial matrix volume is controlled primarily by potassium fluxes and many studies have implicated potassium channels in regulating apoptosis. ${ }^{33,34}$ Furthermore, BCL2 inhibits mitochondrial potassium uptake in some apoptotic models. ${ }^{35}$ Thus, the ABT-737-induced MIMP observed in the present study may be related to a loss of BCL2 regulation of potassium fluxes.

Importantly the ABT-737-induced OMM breaks occurred early in the apoptotic process and were caspase independent (Figure 3). Owing to difficulties in inhibiting BAX and BAK activation in primary cells, we cannot say definitively whether $\mathrm{BAX}$ or BAK are required for OMM breaks. However, the precise localization of BAX and BAK at the OMM breakpoints (Figure 4) strongly suggests that they may be responsible for the OMM rupture. Previously, clusters of BAX have been described as structures adjacent to mitochondria following initial translocation of BAX to mitochondria. ${ }^{36}$ The function of these BAX clusters is unclear and appears to be different from the BAX/BAK associated with OMM break points in the current study. In our study, the association of oligomerized $\mathrm{BAX} / \mathrm{BAK}$ with the $\mathrm{OMM}$ and its consequent pore formation could weaken the OMM so rendering it more susceptible to physical tension induced by swelling of the mitochondrial matrix. This might provide a mechanistic link between oligomerized BAX/BAK and the OMM rupture. Thus BCL2, by inhibiting BAX/BAK activation, may exert a novel role in protecting the IMM and maintaining OMM integrity, in addition to its known role in regulating OMM permeability.

Only a portion of cytochrome $c(\sim 15-20 \%)$ resides in the mitochondrial intermembrane space, while the remainder is stored in the cristae and complete release of cytochrome $c$ during apoptosis involves extensive cristae remodeling by OPA1. ${ }^{37,38}$ Our data, showing that ABT-737 induced a rapid and almost complete release of cytochrome $c$ accompanied by some OPA1 release from CLL mitochondria (Figure 1), are compatible with ABT-737-induced remodeling of mitochondrial cristae. The extensive release of cytochrome $c$ should lead to rapid apoptosome formation and consequent caspase activation, further contributing to the very rapid ABT-737induced apoptosis in CLL cells.

Our data indicate that CLL cells are exquisitely sensitive to $\mathrm{ABT}-737$ ( $\mathrm{EC}_{50}$ of $7 \mathrm{nM}$ at $\left.4 \mathrm{~h}\right)$. Cell lines show wide variations in ABT-737-sensitivity with $\mathrm{EC}_{50}$ values of $8-220 \mathrm{nM}$ at $48 \mathrm{~h}$ in follicular lymphoma cell lines, $0.2-15 \mu \mathrm{M}$ at 24-48 $\mathrm{h}$ in multiple myeloma cell lines, $20 \mathrm{nM}$ to $>100 \mu \mathrm{M}$ at $48 \mathrm{~h}$ in small cell lung cancer cell lines and $190 \mathrm{nM}, 420 \mathrm{nM}$ and $1.3 \mu \mathrm{M}$ at $24 \mathrm{~h}$ in HL60, Jurkat and U937 cells, respectively. ${ }^{18,39-43}$ The relative ABT-737-resistance of many cells has been attributed to high MCL1 levels, as sensitivity has been restored by decreasing cellular MCL1 levels. ${ }^{29,40,42,44-46}$ In marked contrast, the high sensitivity of CLL cells to ABT-737 is largely MCL1 independent (unpublished data). Thus, primary CLL cells appear more sensitive to ABT-737 than all the cell lines studied to date. In this regard, the other primary B-cell malignancies examined in our study have also demonstrated a high sensitivity to ABT-737 with $\mathrm{EC}_{50}$ values at $4 \mathrm{~h}$ of $\sim 13, \sim 11$ and $117 \mathrm{nM}$ for marginal zone, mantle cell and follicular lymphoma cells, respectively. Owing to the smaller numbers of samples currently obtained ( $n=4-7$, Figure 7$)$, these data are not as reliable as those from CLL cells $(n=60)$ but primary malignant $B$ cells appear to be much more sensitive to ABT-737 than many cell lines.

It is possible that this greater sensitivity may relate to the ability of ABT-737 to induce mitochondrial matrix swelling and OMM breaks in these primary malignant $B$ cells (Figures 3 and 7). Few if any such OMM breaks were observed in Jurkat cells exposed to ABT-737 but rather the mitochondria appeared ultracondensed (Figure 7c), as observed in our earlier study. ${ }^{47}$ Ultracondensed mitochondria have also been reported as a consequence of mitochondrial swelling during cell death ${ }^{48}$ but condensed mitochondria were rare in primary leukemia or lymphoma cells following exposure to ABT-737. In preliminary studies, in several human cancer cell lines including several mantle cell lymphoma lines (such as Z138), micromolar concentrations of ABT-737 were required to induce rapid apoptosis. However, in contrast to primary lymphoma cells, this was not accompanied by OMM rupture but rather by the appearance of ultracondensed mitochondria (data not shown). Taken together, our present study raises the possibility that ABT-737-induced apoptosis in primary leukemia or lymphoma cells might occur via a mechanism different from that in cell lines. Such differences may relate to metabolic differences between primary cells and cell lines, which generate their ATP primarily by oxidative phosphorylation or glycolysis, respectively.

In summary, we describe for the first time that targeting of BCL2 by ABT-737 results in a novel paradigm of cell death in primary leukemia and lymphoma cells that involves features of both classical apoptosis and necrosis. This novel mode of cell death may be far more prevalent than hitherto realized, as almost all methods commonly used to assess mitochondrial function or structure, including confocal microscopy, flow cytometry or biochemical assays, would not recognize OMM rupture. CLL cells are exquisitely sensitive to ABT-737 and this may be related to its ability to induce MIMP, matrix swelling and breaks in the OMM, so facilitating extensive release of proapoptotic molecules from the mitochondrial intermembrane space and acting as a strong enhancer of apoptosis. The presence of these OMM breaks in both the primary leukemic and lymphoma cells and their absence in the limited number of cell lines studied to date is intriguing and opens important avenues to explore novel mechanisms of cell survival and chemoresistance. 


\section{Materials and Methods}

Lymphocyte purification and culture. Peripheral blood samples from CLL patients were obtained with patient consent and Local Ethics Committee approval. Lymphocytes were purified and cultured in RPMI-1640 medium supplemented with $10 \%$ FCS and $5 \mathrm{mM}$ L-glutamine (all from Life Technologies Inc., Paisley, UK). All incubations were carried out with $2 \times 10^{6}$ cells per $\mathrm{ml}$.

Reagents. z-VAD.fmk (20-200 $\mu$ M) (MP Biomedicals, Illkirch, France) was used as a broad spectrum caspase inhibitor. Antibodies against COX IV (Cell Signalling, Danvers, MA, USA), cytochrome c (BD Biosciences, San Diego, CA, USA), OPA1 (BD Biosciences), PARP (Alexis Biochemicals, Nottingham, UK), as well as 2-naphthylvinyl ketone (ZM 449829) (Tocris Bioscience, Bristol, UK) and Mitotracker-orange (Molecular Probes, Eugene, OR, USA) were used. ABT-737 was kindly provided by Dr. Saul Rosenberg, Abbott Laboratories, IL, USA.

Activation of BAK and BAX. After treatment, cells were fixed with $2 \%$ paraformaldehyde in PBS at room temperature for 10 min, washed with PBS and stored overnight at $4^{\circ} \mathrm{C}$ in PBS. Fixed cells were resuspended in permeabilization buffer ( $0.1 \%$ saponin and $0.5 \%$ BSA in PBS) and incubated for $1 \mathrm{~h}$ at $4{ }^{\circ} \mathrm{C}$ with $1 \mu \mathrm{l}$ mouse anti-BAX clone $3 \mathrm{Ab}$ (BD Biosciences) or mouse anti-BAK Ab-1 (Calbiochem, Nottingham, UK) diluted in $100 \mu \mathrm{l}$ permeabilization buffer. Goat anti-mouse IgG-Alexa Fluor 488 (Molecular Probes) or biotin-conjugated antimouse IgG (DAKO Cytomation, Cambridge, UK) and PE-conjugated streptavidin (eBioscience, San Diego, CA, USA) were then used for detection of BAX and BAK respectively before analysis with a FACSCalibur (Becton and Dickinson). To analyze BAX translocation, CLL cells were transfected with pEGFP-C1 vector (Clontech, Mountain View, CA, USA) containing BAX using Nucleofector System (Amaxa, Cologne, Germany) and recovered for $12 \mathrm{~h}$ before live cell imaging. Oligomerization of BAX and BAK was assessed in CLL cells following subcellular fractionation. CLL cells were lysed at $4{ }^{\circ} \mathrm{C}$ in hypotonic buffer $(10 \mathrm{mM} \mathrm{NaCl}, 1.5 \mathrm{mM}$ $\mathrm{MgCl}_{2}$ (pH 7.5), $10 \mathrm{mM}$ Tris-HCl) for $10 \mathrm{~min}$ and diluted with MS-buffer $(210 \mathrm{mM}$ mannitol, $70 \mathrm{mM}$ sucrose, $5 \mathrm{mM}$ Tris- $\mathrm{HCl}, 1 \mathrm{mM}$ EDTA) after rupture with a Dounce homogenizer and centrifugation at $1300 \times \mathrm{g}$ for $10 \mathrm{~min}$. Mitochondrial fractions were collected at $17000 \times g$ for $20 \mathrm{~min}$, resuspended in HIM-buffer $(200 \mathrm{mM}$ mannitol, $70 \mathrm{mM}$ sucrose, $10 \mathrm{mM}$ HEPES-KOH, $1 \mathrm{mM}$ EDTA, pH 7.5) and crosslinked with $5 \mathrm{mM}$ Bis-maleimidohexane (Pierce Biotechnology, Rockford, IL, USA) for $30 \mathrm{~min}$. After the reaction was stopped by addition of DTT, fractions were washed with HIM-buffer, collected by centrifugation and diluted in SDS loading dye.

Electron microscopy and immunogold labeling. Isolated mitochondrial fractions were fixed for $5 \mathrm{~min}$ in $4 \%$ paraformaldehyde in buffer containing $220 \mathrm{mM}$ mannitol, $68 \mathrm{mM}$ sucrose, $20 \mathrm{mM}$ HEPES-KOH, $10 \mathrm{mM} \mathrm{KCl}$, $1.5 \mathrm{mM} \mathrm{MgCl}_{2}, 1 \mathrm{mM}$ EDTA-Na, $1 \mathrm{mM}$ EGTA-Na, $1 \mathrm{mM}$ DTT, $0.1 \mathrm{mM}$ PMSF labeled with anti-BAX clone $3 \mathrm{Ab}$ (BD Biosciences) or anti-BAK Ab-1 (Calbiochem) and goat anti-mouse IgG Ab-conjugated with $10 \mathrm{~nm}$ gold (BB International, Cardiff, UK). These fractions, like the intact cells, were fixed and processed for electron microscopy as described previously. ${ }^{26,47}$ Electron micrographs were recorded using either a QICAM 12-bit Mono Fast 1394 digital camera and QCapture-Pro software (MAG, Pleasanton, CA, USA) or Kodak 4489 film, in a Zeiss 902A electron microscope. Negatives were scanned at 2000 dots per inch and all digital images were optimized, using auto-levels, before being annotated and arranged using Adobe Photoshop CS3. To avoid subjective interpretation, the percentage of cell profiles containing severely swollen mitochondria and exhibiting OMM discontinuities were estimated by measuring the changes in control and treated cells in blinded fashion.

Determination of apoptosis. Cells were treated with ABT-737 and apoptosis assessed either by PS externalization using AnnexinV/FITC in the presence of propidium iodide (PI) or by loss of $\Psi \mathrm{m}$ using $50 \mathrm{nM}$ TMRE (Molecular Probes), as described previously. ${ }^{49}$ Release of mitochondrial cytochrome $c$ from CLL cells was measured essentially as described previously. ${ }^{27}$ Briefly, $10 \times 10^{6}$ cells were washed in cold PBS and resuspended in mitochondrial isolation buffer (250 mM sucrose, $20 \mathrm{mM} \mathrm{HEPES,} \mathrm{pH} \mathrm{7.4,} 5 \mathrm{mM} \mathrm{MgCl}_{2}$ and $10 \mathrm{mM} \mathrm{KCl}$ ) containing $0.05 \%$ digitonin. Cells were left on ice for $10 \mathrm{~min}$ followed by centrifugation at 13000 r.p.m. for $3 \mathrm{~min}$. Subsequently, supernatant and pellets were analyzed by western blotting and stained with anti-cytochrome $c \mathrm{Ab}$ (BD Biosciences) or antiOPA1 Ab (BD Biosciences)
Flow sorting. CLL cells were exposed to ABT-737 $(10 \mathrm{nM})$ for $2 \mathrm{~h}$ before staining with TMRE $(25 \mathrm{nM})$. Following staining, $5 \times 10^{6}$ cells were sorted into TMRE high and TMRE low populations directly into $2 \times$ concentrated fixative $(4 \%$ glutaraldehyde in $0.1 \mathrm{M}$ sodium cacodylate). The sorted cells were collected by centrifugation and processed for electron microscopy.

Measurement of MIMP. MIMP is most often associated with PTP opening but it can also be caused by other alterations in IMM permeability. ${ }^{9,10,12,13}$ MIMP was assessed using the calcein/cobalt method with minor modifications to the previously described method. ${ }^{24,25} \mathrm{CLL}$ cells were adjusted to $5 \times 10^{6}$ cells per ml with RPMI1640 supplemented with $10 \%$ FCS. Calcein.AM (100 nM, Invitrogen, Paisley, UK) was added together with $\mathrm{CoCl}_{2}(1 \mathrm{mM}$, Sigma). The cell suspension was incubated at $37^{\circ} \mathrm{C}$ for $30 \mathrm{~min}$ and washed once with an equal volume of fresh medium without calcein and $\mathrm{CoCl}_{2}$. Cells were then exposed to ABT-737 for the indicated times and supplemented with $\mathrm{CaCl}_{2}(1 \mathrm{mM}), 10 \mathrm{~min}$ before the end of treatment. Annexin V-APC conjugates (Invitrogen) were added according to the manufacturer's instructions to detect PS externalization. Hoechst $33342(250 \mathrm{ng} / \mathrm{ml})$ was also added to the cell cultures to visualize the nuclei. Fluorescent changes were then detected using a Zeiss LSM 510 laser scanning confocal microscope.

Acknowledgements. We are grateful to Mrs Judy McWilliam, Mr Roger Snowden, Dr. Satoshi Inoue and Ms Kathrin Weber for their invaluable assistance. We thank Dr. Ed Bampton for the pEGFP-C1-BAX vector. We thank Professor John Lemasters for helpful discussions concerning the calcein/cobalt method and Dr. Saul Rosenberg for ABT-737.

1. Adams JM, Cory S. The Bcl-2 apoptotic switch in cancer development and therapy. Oncogene 2007; 26: 1324-1337.

2. Danial NN, Korsmeyer SJ. Cell death: critical control points. Cell 2004; 116: 205-219.

3. Chen L, Willis SN, Wei A, Smith BJ, Fletcher JI, Hinds MG et al. Differential targeting of prosurvival $\mathrm{Bcl}-2$ proteins by their $\mathrm{BH} 3$-only ligands allows complementary apoptotic function. Mol Cell 2005; 17: 393-403.

4. Willis SN, Chen L, Dewson G, Wei A, Naik E, Fletcher Jl et al. Proapoptotic Bak is sequestered by $\mathrm{Mcl}-1$ and $\mathrm{Bcl}-\mathrm{xL}$, but not $\mathrm{Bcl}-2$, until displaced by $\mathrm{BH} 3$-only proteins. Genes Dev 2005; 19: 1294-1305.

5. Willis SN, Fletcher Jl, Kaufmann T, van Delft MF, Chen L, Czabotar PE et al. Apoptosis initiated when BH3 ligands engage multiple Bcl-2 homologs, not Bax or Bak. Science 2007; 315: 856-859.

6. Kroemer G, Galluzzi L, Brenner C. Mitochondrial membrane permeabilization in cell death. Physiol Rev 2007; 87: 99-163.

7. Rasola A, Bernardi $P$. The mitochondrial permeability transition pore and its involvement in cell death and in disease pathogenesis. Apoptosis 2007; 12: 815-833.

8. Vander Heiden MG, Chandel NS, Williamson EK, Schumacker PT, Thompson CB. Bcl-xL regulates the membrane potential and volume homeostasis of mitochondria. Cell 1997; 91: $627-637$.

9. Lee WK, Thevenod F. A role for mitochondrial aquaporins in cellular life-and-death decisions? Am J Physiol Cell Physiol 2006; 291: C195-C202.

10. Chipuk JE, Bouchier-Hayes L, Green DR. Mitochondrial outer membrane permeabilization during apoptosis: the innocent bystander scenario. Cell Death Differ 2006; 13: 1396-1402.

11. Forte M, Bernardi $P$. The permeability transition and BCL-2 family proteins in apoptosis: $\mathrm{CO}^{-}$ conspirators or independent agents? Cell Death Differ 2006; 13: 1287-1290.

12. Gazaryan IG, Brown AM. Intersection between mitochondrial permeability pores and mitochondrial fusion/fission. Neurochem Res 2007; 32: 917-929.

13. Green DR, Kroemer G. The pathophysiology of mitochondrial cell death. Science 2004; 305: 626-629.

14. Belzacq AS, Vieira HL, Kroemer G, Brenner C. The adenine nucleotide translocator in apoptosis. Biochimie 2002; 84: 167-176.

15. Halestrap AP, Brenner $\mathrm{C}$. The adenine nucleotide translocase: a central component of the mitochondrial permeability transition pore and key player in cell death. Curr Med Chem 2003: 10: 1507-1525.

16. Baines CP, Kaiser RA, Sheiko T, Craigen WJ, Molkentin JD. Voltage-dependent anion channels are dispensable for mitochondrial-dependent cell death. Nat Cell Biol 2007; 9 : 550-555.

17. He L, Lemasters JJ. Regulated and unregulated mitochondrial permeability transition pores: a new paradigm of pore structure and function? FEBS Lett 2002; 512: 1-7.

18. Oltersdorf T, Elmore SW, Shoemaker AR, Armstrong RC, Augeri DJ, Belli BA et al. An inhibitor of Bcl-2 family proteins induces regression of solid tumours. Nature 2005; 435: 677-681.

19. Zhai D, Jin C, Satterthwait AC, Reed JC. Comparison of chemical inhibitors of antiapoptotic Bcl-2-family proteins. Cell Death Differ 2006; 13: 1419-1421.

20. Packham G, Stevenson FK. Bodyguards and assassins: Bcl-2 family proteins and apoptosis control in chronic lymphocytic leukaemia. Immunology 2005; 114: 441-449. 
36. Nechushtan A, Smith CL, Lamensdorf I, Yoon SH, Youle RJ. Bax and Bak coalesce into novel mitochondria-associated clusters during apoptosis. J Cell Biol 2001; 153 1265-1276.

37. Frezza C, Cipolat S, Martins de Brito O, Micaroni M, Beznoussenko GV, Rudka T et al. OPA1 controls apoptotic cristae remodeling independently from mitochondrial fusion. Cell 2006; 126: 177-189.

38. Scorrano L, Ashiya M, Buttle K, Weiler S, Oakes SA, Mannella CA et al. A distinct pathway remodels mitochondrial cristae and mobilizes cytochrome $c$ during apoptosis. Dev Cell 2002: 2: 55-67.

39. Chauhan D, Velankar M, Brahmandam M, Hideshima T, Podar K, Richardson P et al A novel $\mathrm{Bcl}-2 / \mathrm{Bcl}-\mathrm{X}(\mathrm{L}) / \mathrm{Bcl}-\mathrm{w}$ inhibitor ABT-737 as therapy in multiple myeloma. Oncogene 2007; 26: 2374-2380.

40. Chen S, Dai Y, Harada H, Dent P, Grant S. Mcl-1 down-regulation potentiates ABT-737 lethality by cooperatively inducing Bak activation and Bax translocation. Cancer Res 2007; 67: 782-791.

41. Kline MP, Rajkumar SV, Timm MM, Kimlinger TK, Haug JL, Lust JA et al. ABT-737, an inhibitor of Bcl-2 family proteins, is a potent inducer of apoptosis in multiple myeloma cells. Leukemia 2007; 21: 1549-1560.

42. Tahir SK, Yang X, Anderson MG, Morgan-Lappe SE, Sarthy AV, Chen J et al. Influence of Bcl-2 family members on the cellular response of small-cell lung cancer cell lines to ABT737. Cancer Res 2007; 67: 1176-1183.

43. Trudel S, Stewart AK, Li Z, Shu Y, Liang SB, Trieu Y et al. The Bcl-2 family protein inhibitor, ABT-737, has substantial antimyeloma activity and shows synergistic effect with dexamethasone and melphalan. Clin Cancer Res 2007; 13: 621-629.

44. Dai Y, Grant S. Targeting multiple arms of the apoptotic regulatory machinery. Cancer Res 2007; 67: 2908-2911.

45. Konopleva M, Contractor R, Tsao T, Samudio I, Ruvolo PP, Kitada S et al. Mechanisms of apoptosis sensitivity and resistance to the $\mathrm{BH} 3$ mimetic ABT-737 in acute myeloid leukemia. Cancer Cell 2006; 10: 375-388.

46. Lin X, Morgan-Lappe S, Huang X, Li L, Zakula DM, Vernetti LA et al. 'Seed' analysis of offtarget siRNAs reveals an essential role of Mcl-1 in resistance to the small-molecule Bcl-2/ Bcl-X(L) inhibitor ABT-737. Oncogene 2007; 26: 3972-3979.

47. Zhuang J, Dinsdale D, Cohen GM. Apoptosis, in human monocytic THP.1 cells, results in the release of cytochrome $c$ from mitochondria prior to their ultracondensation, formation of outer membrane discontinuities and reduction in inner membrane potential. Cell Death Differ 1998; 5: 953-962.

48. Shchepina LA, Pletjushkina OY, Avetisyan AV, Bakeeva LE, Fetisova EK, Izyumov DS et al. Oligomycin, inhibitor of the F0 part of H+-ATP-synthase, suppresses the TNF-induced apoptosis. Oncogene 2002; 21: 8149-8157.

49. Inoue S, MacFarlane M, Harper N, Wheat LM, Dyer MJ, Cohen GM. Histone deacetylase inhibitors potentiate TNF-related apoptosis-inducing ligand (TRAIL)-induced apoptosis in lymphoid malignancies. Cell Death Differ 2004; 11 (Suppl 2): S193-S206.

35. Eliseev RA, Gunter KK, Gunter TE. Bcl-2 sensitive mitochondrial potassium accumulation and swelling in apoptosis. Mitochondrion 2002; 1: 361-370.

\section{Supplementary Information accompanies the paper on Cell Death and Differentiation website (http://www.nature.com/cdd)}

